\title{
EDUCAÇÃO, IDEOLOGIA E DISCURSO: UMA ANÁLISE CRÍTICA E MULTIMODAL DA SÉRIE DE REPORTAGENS “BLITZ EDUCAÇÃO”
}

\author{
Laura Jorge Nogueira Cavalcanti ${ }^{1}$
}

\begin{abstract}
RESUMO
Neste artigo, examinamos a série de reportagens intitulada "Blitz Educação", veiculada pela Rede Globo em seu principal noticiário, Jornal Nacional, em maio de 2011, a fim de elucidar as concepções de educação formal que circulam na grande mídia (aqui representada pela emissora), bem como o papel atribuído ao/a professor/a no processo educacional. Buscamos apoio na Análise Crítica do Discurso, em seu principal expoente Norman Fairclough (2001; 2003), fazendo uma ponte com o desenvolvimento sobre ideologia e relações de poder entre grupos sociais com Teun A. van Dijk (2006; 2010), e na análise multimodal de textos imagéticos, proposta por Kress e van Leeuwen (1996). Para contextualizar as concepções pedagógicas postas em discussão ao longo da série, realizamos um apanhado das principais correntes a guiar a educação formal no Brasil, examinando os Parâmetros Curriculares Nacionais (1997) e outras fontes. Tendo em vista que o recurso semiótico multimodal disponibilizado pelas imagens é um poderoso recurso na construção do discurso, examinamos as escolhas de montagem e edição das imagens, os processos narrativos de representação, bem como as construções conceituais de representação realizados na série. Ao final, observamos como, através de estruturas de lexicalização, de construção da transitividade, dos recursos semióticos multimodais, dentre outros, enquadra-se o/a professor/a como único responsável pelo sucesso/fracasso do processo educativo formal. Ainda testemunhamos como, através do discurso (verbal e imagético) e apoiada nessa caracterização do profissional docente, a série de reportagens impõe uma ideologia hegemônica e conservadora sobre a educação.
\end{abstract}

Palavras-chave: Educação. Análise crítica do discurso. Multimodalidade.

\section{INTRODUÇÃO}

Durante a semana de 16 a 21 de maio de 2011, a Rede Globo, em seu Jornal Nacional, realizou uma série jornalística intitulada "Blitz Educação". Durante a série, que foi ao ar com um episódio a cada dia da semana, 10 escolas das 05 regiões do País foram visitadas pelos repórteres da emissora e suas afiliadas e pelo especialista em educação, Gustavo loschpe. O objetivo era mostrar as condições físicas das escolas, o dia a dia dos alunos e professores, a formação acadêmica e salário dos professores, os materiais usados, dentre outros aspectos que 
explicariam a nota obtida por cada escola no Índice de Desenvolvimento da Educação Básica (ldeb). Em cada cidade sorteada, duas escolas eram selecionadas: uma com boa nota no Ideb e outra com nota baixa. Diariamente durante essa semana, o Jornal Nacional exibiu as reportagens, que tinham entre 07 e 10 minutos de duração, mostrando imagens das escolas em funcionamento, contendo depoimentos dos professores e professoras, entrevistas com as diretoras e diretores, com os familiares e comentários por Gustavo loschpe. Segundo as declarações feitas ao longo da série, buscou-se fazer um retrato da situação da educação no Brasil, tendo assim um caráter documental e, talvez, até de denúncia.

Porém, o papel da mídia jornalística de vigilante social vem sendo questionado cada vez mais. Segundo Martins (2005, p. 130), "a realidade tem mostrado que a imprensa é atravessada ela mesma por interesses os mais diversos, frequentemente difusos e antagônicos", ou seja, a imprensa (e a mídia jornalística em geral), composta por diferentes atores sociais como ela é, apresenta-se como arena de conflito, um domínio aberto a ideologias contrastantes. Por esse motivo, e considerando que mídia em geral (e televisiva em particular) tem ganhado cada vez mais espaço e exposição, os discursos difundidos, elaborados e reelaborados nesse meio têm sido objeto de interesse de analistas críticos do discurso. A Análise Crítica do Discurso (ACD) se coloca como uma agenda de trabalho que pretende questionar e problematizar discursos produzidos e distribuídos de forma a perpetuar relações assimétricas de poder, ou seja, o emprego do discurso a favor da dominação por um grupo sobre outro(s). Tendo em vista que a Rede Globo de televisão tem em seu Jornal Nacional um dos programas de notícias mais prestigiosos do País, cabe uma revisão crítica (linguística, discursiva e social) de uma série que pretende discutir um tema (educação) que vem sendo cada vez mais “apropriado" pela grande mídia. Portanto, há de se questionar o porquê dessa série ter ido ao ar, quem a produziu, quem está falando sobre a educação, quem não está falando, o quê está sendo dito, como está sendo dito, etc.

A presente análise pretende investigar se o discurso construído durante a série elege uma versão de educação em detrimento de outras, partindo de um ponto assimétrico de poder sobre o discurso, tendo assim, possivelmente, um caráter prescritivo e normativo. Através da investigação de como é posto o papel do/a professor/a, pretende-se analisar como o tratamento deste agente da educação serve de fundação para a concepção do processo de educação como um todo. 
Objetivos mais específicos deste estudo incluem a análise da seleção, acesso à fala e à produção dos discursos, evidenciando relações de poder produzidas ou reproduzidas nas reportagens; investigar como são (des)legitimadas as palavras de diferentes grupos e de diferentes discursos, através da identificação de processos de legitimação e de hegemonização discursiva; considerar os recursos multimodais e sua contribuição para a (re)produção de discursos ideologicamente investidos nas reportagens.

Para facilitar a consideração das observações, o estudo será tematicamente dividido em duas partes: (i) investigação do conceito de educação que se constrói ao longo das reportagens e (ii) como é caracterizado o profissional docente (generalizado a partir dos profissionais particulares presentes na reportagem e nos comentários sobre esse grupo em geral) por meio de qualificações, avaliações, agência, etc. Quanto aos níveis de análise, por se tratar de um corpus composto de matérias televisivas, ambos os temas serão analisados em termos de seu desenvolvimento discursivo verbal e imagético.

\section{A CONSTRUÇÃO E PRESCRIÇÃO DE UM CONCEITO DE EDUCAÇÃO}

Ao longo das reportagens da série "Blitz Educação", constrói-se através do discurso, certo conceito sobre educação - como acontece, para que finalidade, para quem, quem participa, quais são seus papéis e deveres, etc. - que reflete certas ideias sobre o processo mesmo de ensino-aprendizagem. Sempre comparando duas escolas em cada episódio, sendo que uma com um conceito baixo e outra com um conceito alto no Ideb, as reportagens vão classificando as escolas em duas categorias - as "boas" e as "ruins", o que coloca as duas instituições em uma situação de oposição/polarização. A polarização entre as escolas (e os atores sociais que atuam em cada um desses espaços) é problemática por vários motivos, mas mais ainda por corroborar a simplificação do processo educacional que, na verdade, é altamente complexo. Além disso, remete à dicotomia essencial ao trabalho ideológico, apontada por van Dijk (2006; 2010): "Nós" x "Eles", que permeia todo o discurso construído nas reportagens e instiga o público a escolher um lado.

Essa simplificação do processo educacional fica evidente quando, ao se falar de boa educação, das escolas com notas altas no Ideb, listam-se medidas e 
características muito ao estilo de uma receita propriamente dita. Por exemplo, neste trecho do $1^{\circ}$ episódio, em que o repórter André Luiz Azevedo diz:

Vamos descobrindo, juntos, o que faz a diferença nesta escola. Ela [diretora] quer ampliar as aulas em mais duas horas. [...] Limpeza. Disciplina [...] Organização. Cuidado com as crianças. Equipamentos modernos sendo usados, e atividades extracurriculares também. (Episódio 01, 2:15 - 2:45).

Em sua listagem das medidas positivas para a educação, se apaga toda uma gama de dificuldades e obstáculos enfrentados no processo de ensinoaprendizagem. Apagam-se os tons de cinza e foca-se na educação como se fosse possível vê-la em preto e branco. Esse mesmo tipo de listagem é realizado várias vezes ao longo dos episódios, sendo às vezes reforçada por legendas que sobrepõem à imagem, como se vê na Figura 01 (Episódio 03, 6:37). Fica bastante claro, também, pelas próprias diretrizes indicadas, que a perspectiva pedagógica prescrita nas reportagens assemelha-se à perspectiva tradicionalista, em que "o que orienta é a organização lógica das disciplinas, o aprendizado moral, disciplinado e esforçado" (BRASIL, 1997, p. 31).

\section{Figura 01 - Blitz Educação, Episódio 03}

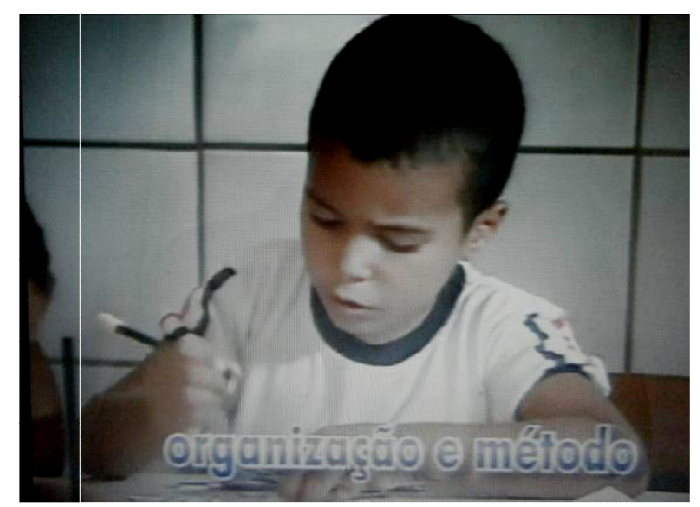

O discurso verbal e imagético, tecido através das falas do repórter, das legendas e imagens captadas, reforça uma única ideia: há escolas boas e escolas ruins. As escolas (e todos os seus integrantes) boas são escolas em que "disciplina", "organização" e "método" existem. As escolas ruins não seguem esses princípios.

\section{A CARACTERIZAÇÃO DOIA PROFESSOR/A}

O profissional docente sempre foi considerado, por motivos óbvios, essencial no processo de educação formal. Porém, de acordo com as diferentes correntes 
pedagógicas, os/as professores/as assumem diferentes papéis nesse processo. Fazendo referência às quatro principais tendências pedagógicas no Brasil, apontadas nos PCNs, tem-se que, numa perspectiva tradicionalista, o/a professor/a deve ser a autoridade máxima, detentor de todo conhecimento, responsável por, além de ensinar os conteúdos, "vigiar os alunos"; numa perspectiva da pedagogia renovada, o/a professor/a é visto não mais como centro do processo, mas como facilitador do mesmo; para a pedagogia tecnicista, o/a professor/a tem o papel somente de aplicar as tecnologias e métodos (simples instrumento); finalmente, como coordenador de atividades que atua conjuntamente com os alunos, dentro da pedagogia libertadora. Tendo em vista que essas quatro tendências concorrem a todo momento, tanto no nível da sala de aula (em termos das práticas e didática utilizadas) quanto no nível social, mais abrangente (em termos dos discursos construídos que defendem uma ou outra corrente), algumas vezes serão identificados elementos de uma ou de outra tendência em certas construções discursivas (verbais ou imagéticas).

Em todas as 06 reportagens da série, os professores são caracterizados através dos atributos de formação acadêmica, tempo de experiência como docentes e salário recebido. Nessa constante classificação e enquadramento dos/as professores/as, realizada não só verbalmente, mas também graficamente através de legendas (como ilustrado na Figura 02), há um efeito de padronização que desumaniza a figura do profissional, tratando-o objetivamente.

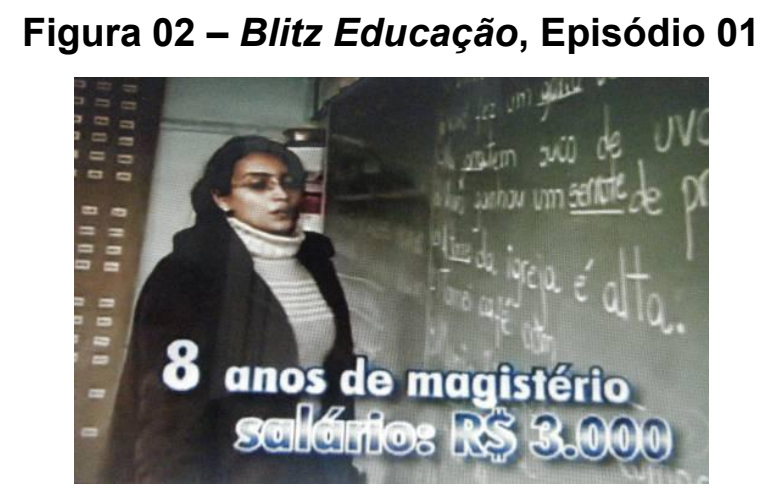

Porém, o critério definidor de sucesso do trabalho do educador em termos de ensino-aprendizagem, tende a ser mostrado como algo que independe desses três fatores descritores, e é colocado como algo subjetivo, relativo e pessoal. Por exemplo, no episódio de número 02, o repórter André Luiz Azevedo, ao introduzir a matéria, diz: "Mesmo nesse ambiente [...] um professor de qualidade, com boa 
formação, com competência, com dedicação, com material, pode fazer a diferença e dar um ambiente de qualidade para os alunos" (Episódio 02, 3:38 - 3:48). Contudo, é difícil precisar (se não impossível chegar a um consenso sobre) o que é um professor de qualidade e o que se entende por competência e dedicação. A simplificação e naturalização (THOMPSON, 1995) da ideia do "bom" professor acarreta um preconceito infundado com aqueles que não conseguem realizar um trabalho "de qualidade" segundo a visão da rede de televisão que comanda a matéria, classificando os profissionais docentes simplesmente em termos de "bom" $\mathrm{x}$ "mau".

Além dessa polarização ou fragmentação do grupo (uma estratégia de dominação ideológica, segundo van Dijk (2006)), os/as professores/as são caracterizados como atores sociais diretamente e quase que exclusivamente responsabilizados pelo sucesso ou fracasso dos alunos nas avaliações, como pode ser observado na fala da repórter Beatriz Castro, da afiliada da Rede Globo no Nordeste:

Quem sabe mais motivado, o professor possa transformar dois dados preocupantes: na população com mais de quinze anos, a taxa de analfabetismo no nordeste é de $19,1 \%$, quase o dobro da média nacional, que é de $9,6 \%$. E o abandono escolar, que chega a $15 \%$ nas séries finais do ensino fundamental. (Episódio 03, 1:58 - 2:23).

Nessa fala, vê-se que o/a professor/a é enquadrado/a como o/a agente responsável pela taxa de analfabetismo e de abandono escolar, ou seja, pelo fracasso ou sucesso escolar. Observa-se esse enquadramento em quase todos os episódios da série.

Quando se utiliza a língua, realizam-se escolhas - estruturais, lexicais, modalizadoras, etc. Essas escolhas linguístico-discursivas são impregnadas e motivadas (mesmo que inconscientemente) por ideologias que acusam a posição do ator social que produz aquele discurso. Fairclough (2001, p. 104) sugere que:

Toda oração é multifuncional e, assim, toda oração é uma combinação de significados ideacionais, interpessoais (identitários e relacionais) e textuais [...]. As pessoas fazem escolhas sobre o modelo e a estrutura de suas orações que resultam em escolhas sobre o significado (e a construção) de identidades sociais, relações sociais e conhecimento e crença.

De modo que é preciso atentar para as escolhas que estão sendo feitas nos enunciados proferidos pelos que têm acesso ao discurso, que têm acesso à distribuição do discurso, que falam de uma posição de legitimidade, como por 
exemplo, a grande mídia, ou nesse caso específico, os jornalistas e especialistas convocados pela Rede Globo. Esses jornalistas e especialistas não falam/agem no vácuo, mas de uma posição enquanto atores sociais que trabalham para aquele veículo jornalístico específico, e que são assim constrangidos a adotar a visão de mundo daquele veículo (ou pelo menos não se opor diretamente a ela em seu discurso).

\section{ANÁLISE MULTIMODAL}

Tradicionalmente, em ACD, faz-se análise de discursos com apoio em textos empíricos verbais. Porém, cada vez mais se tem atentado para textos não verbais, mais especificamente, imagéticos. No caso desse estudo, em se tratando de discursos construídos em matérias de televisão, a imagem tem lugar tão importante quanto o verbal. Por isso, o olhar ao texto imagético, em termos críticos como resultados de escolhas ideologicamente investidas, espaços de construção de sentidos, de formas discursivas que trabalham para a subversão ou reprodução de posições de dominação.

Considerando-se os textos imagéticos como unidades empíricas de análise, pode-se, com Kress e van Leeuwen (1996), tentar buscar categorias para análise desses textos, da mesma forma que se buscaria para a análise de textos verbais, com as ressalvas de que (i) os autores tratam primariamente de textos imagéticos estáticos (fotografias, ilustrações, diagramas, anúncios de revista, etc.), apesar de abordarem em um curto capítulo especialmente textos fílmicos e (ii) nem sempre é possível se realizar uma análise da imagem da mesma forma que se realizaria uma análise do texto verbal.

Consideradas as ressalvas, alguns processos de discursivização a serem examinados que podem ser adaptados para a análise de vídeo são: os processos narrativos de representação (onde se examina os actors, vetores e objetos envolvidos) $^{2}$, as construções conceituais de representação (de classificação, analíticas e simbólicas) ${ }^{3}$. Além desses processos, categorias como modalização (modality) e composição (composition), serão analisadas em termos da construção de sentidos. É importante lembrar nesse momento, que, em se tratando de um meio de realização dinâmico como o filme, os processos e representações estão em 
constante elaboração e reelaboração, o que demanda uma análise bastante minuciosa e multinivelada a cada quadro.

Além disso, pretende-se explorar o papel do trabalho de edição/montagem na construção de sentidos, por considerar com Squirra (2008) que:

Objetivamente falando, aponto que a edição, no telejornal, nunca é isenta. Concluo dessa forma após constatar que ela possibilita infinitos modelos de intenção construtiva e seleção de conteúdos. Quer seja pela formação cultural e política do codificador (o repórter), ou ainda pelo perfil empresarial da emissora e de seu proprietário, o momento editorial da emissora frente aos entes públicos (políticos, empresas, governos, atores etc.), os compromissos empresariais do grupo que controla a emissora, a força regional e nacional de empresas e representantes do povo etc.

Apesar de ser virtualmente impossível saber exatamente que imagens foram cortadas e em que ordem elas apareceram originalmente no decorrer das filmagens, em alguns momentos, o trabalho de edição/montagem evidencia-se de tal forma que se presta à análise autorizada de seus possíveis intentos e efeitos discursivos.

\subsection{Análise de processos narrativos de representação}

As reportagens da série "Blitz Educação" compõem no total uma narrativa que conta uma história sobre a "descoberta" da "real" situação da educação no Brasil pela equipe do Jornal Nacional. Essa história, como outras narrativas, é composta por participantes ou actors, em termos da análise multimodal proposta por Kress e van Leeuwen (1996). Os actors, que realizam a ação (seja de entrevistar, de conhecer, de entender), direcionam essa ação aos objetos (nesse caso, professores, as escolas, a própria situação da educação). As ações realizadas pelos actors, por sua vez, são representadas visualmente como vetores. Em termos de um texto fílmico, esses vetores são realizados por movimentos como o caminhar para a escola, o assistir uma aula, o pegar um livro didático para ler, o entrevistar um/a professor/a. Durante toda a série, tem-se o repórter da Rede Globo, André Luiz Azevedo e o especialista convocado pela emissora, Gustavo loschpe, como os actors (que realizam as atividades). Já os objetos (professores, diretores, escolas, alunos) são sempre representados na narrativa, como participantes passivos (represented participants).

Ainda em termos de processos narrativos de representação, é relevante observar as circunstâncias em que se dá essa narrativa (setting, means e 
accompaniment, nos termos dos autores), que corresponderia à ambientação, em termos narrativos clássicos - que espaços, quanto desses espaços, e com que foco esses espaços são mostrados, em que os actors exercem suas ações, através de que meios exercem essas ações e quais os participantes não envolvidos que aparecem também. Normalmente, os espaços em que aparecem os actors são as próprias escolas e as salas de aula. Os ambientes são mostrados de forma clara, bem focalizados, e de diferentes ângulos, normalmente naturais à visão, a fim de realizar uma modalização naturalista. Esse estilo de modalização, segundo Kress e van Leeuwen (2006), tenta ser o mais realista possível (sem efeitos especiais ou de iluminação) em sua representação - o que corresponde ao gênero matéria jornalística e sustenta a ilusão de objetividade intrínseca a esta ordem do discurso. É importante lembrar com os autores que:

Uma teoria semiótica social da verdade não pode estabelecer a absoluta verdade ou falsidade de representações. Ela pode somente evidenciar se uma dada 'proposição' [...] é representada como verdadeira ou não. Do ponto de vista da semiótica social, a verdade é um construto da semiose. (KRESS; VAN LEEUWEN, 1996, p. 154). ${ }^{4}$

Portanto, por utilizar-se nas reportagens uma modalização naturalista, tem-se a impressão de que o que está sendo mostrado (a proposição a que se referem os autores), bem como a forma como está sendo mostrado, corresponde à realidade. Esse efeito (ou essa ilusão) é, todavia, buscado nas produções discursivas do meio jornalístico (seja em produções verbais, com a utilização de estruturas linguísticas como o modo indicativo, ou imagéticas, através de uma modalização naturalista), que ainda trabalha sob o mito da objetividade.

\subsection{Análise das construções conceituais de representação}

As construções conceituais de representação contribuem para o entendimento da essência/identidade mais ou menos estável dos participantes envolvidos na narrativa imagética. Em geral, observa-se que os professores são filmados dentro de sala de aula (no quadro, falando com alunos individualmente, ou com os repórteres). Esse enquadramento, ou padrão conceitual (nos termos de Kress e van Leeuwen), apresentado para se considerar a figura do/a professor/a, sugere que este profissional apenas trabalha dentro de sala de aula. Tem-se, portanto, a exclusão de vários outros aspectos do trabalho do/a professor/a: 
reuniões pedagógicas, correção de tarefas e provas, atualização da caderneta, reuniões de planejamento, reuniões de pais e professores, cursos de formação continuada, etc. A redução do trabalho docente ao trabalho em sala de aula é uma simplificação que exclui outras contingências na vida destes profissionais e respalda a visão de que o/a professor/a teria apenas uma responsabilidade: ensinar os conteúdos (numa visão pedagógica tradicionalista ou tecnicista). Essa representação imagética simplificadora e reducionista corrobora a redução decorrente dos efeitos de sentido do discurso verbal analisados anteriormente.

Já a figura do especialista (além de Gustavo loschpe, pois, este está em uma situação de mobilidade) aparece contextualizada em lugares próprios de especialistas (escritórios com estantes e livros, ou a própria sala de aula vazia). Um ou outro é contextualizado em ambiente diverso, porém sempre contendo elementos que remetem à intelectualidade ou erudição: obras de arte, prédios históricos, campus universitários, etc. Essa contextualização espacial serve para reforçar o papel do especialista - enquanto um expert, cuja fala deve ser tomada como legítima pela autoridade que representa (VAN LEEUWEN, 1986).

As representações conceituais dos participantes envolvidos nas reportagens são escolhidas e selecionadas por contribuírem para a construção do discurso sobre educação, sobre o papel dos/as professores/as pela emissora. De certa forma, esse discurso é classificatório, pois posiciona cada grupo de participantes em um determinado papel (o/a especialista que tem autoridade, o/a professor/a que tem um dever enquanto instrumento do processo de educação). Essas classificações, naturalizadas pela série, porém, não devem ser tomadas como naturais, e sim, como convencionadas ao longo da história, inclusive pela reprodução de discursos como esse. Kress e van Leeuwen (1996) alertam:

\footnotetext{
Processos de classificação não refletem simplesmente classificações 'reais' ou 'naturais'. O fato de que os participantes sejam colocados juntos em um sintagma que estabeleça uma classificação significa que eles foram julgados como membros da mesma classe, e devem ser lidos como tal. 'Naturalização' não é natural, seja em imagens ou na língua. (KRESS; LEEUWEN, 1996, p.79. Grifo do autor) ${ }^{5}$.
}

Mais uma vez, encontram-se processos de naturalização (em representações e classificações) pelo discurso, que podem servir para a reprodução e perpetuação de relações assimétricas de poder e dominação. 


\subsection{Interação com o espectador e modalização}

As representações narrativas e conceituais construídas em imagens (tanto estáticas quanto móveis) estabelecem relações com o espectador de diferentes formas: através dos ângulos da câmera, através da perspectiva adotada, através do olhar do participante/ator na imagem, etc. concebidas por Kress e van Leeuwen (1996) como evidenciando o tipo de contato entre participante e espectador, a distância entre espectadores e participantes, e o posicionamento pretendido ${ }^{6}$.

Como já foi ressaltado antes, porque são reportagens jornalísticas, as imagens trazem uma modalização naturalista, o que quer dizer que as imagens tentam representar em vídeo o mais próximo possível o que se veria naturalmente. Sendo assim, há poucos momentos em que recursos mais ousados de interação com o espectador são mobilizados por não serem muito realistas em sua forma de execução. Por exemplo, em termos de distância entre os participantes capturados em filme e os espectadores (câmera), quase sempre há uma distância socialmente convencionada (social distance), a não ser quando os participantes enfocados são os alunos (quando se usa o close-up, um quadro fechado mais próximo do rosto do aluno, o que sugere intimidade e incita empatia), ou os especialistas (em que se usa o breast pocket, quando o especialista é mostrado da cintura para cima, evidenciando certa proximidade, mas ainda certa distância por respeito à autoridade).

Em termos de posicionamento (attitude), as reportagens alternam entre posicionamentos objetivos e subjetivos, construídos através da angulação da câmera. O que chama a atenção é que o posicionamento subjetivo (que provoca maior envolvimento do espectador) está reservado a certos quadros: aqueles em que o/a aluno/a aparece, ou que são supostamente do ponto de vista do/a aluno/a, gerando envolvimento e empatia, enquanto que professores são mostrados por ângulos oblíquos, que geram um sentimento de desconexão com o participante. Isso fica claro no Episódio 02, quadro ilustrado na Figura 03, por exemplo. 


\section{Figura 03 - Blitz Educação, Episódio 02}

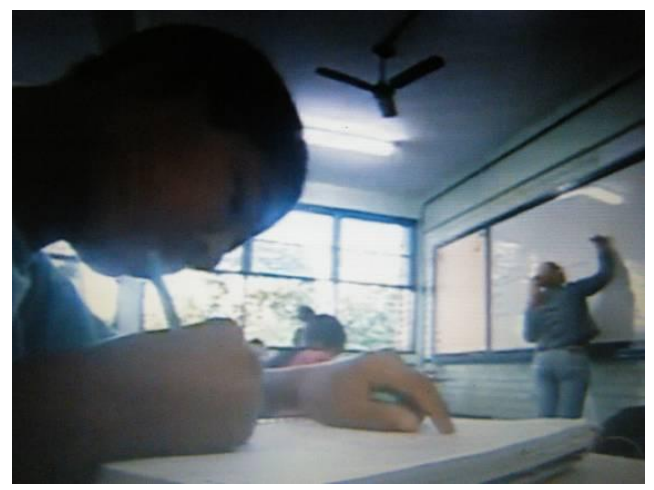

\subsection{Análise do trabalho de edição/montagem}

Como foi apontado anteriormente, com Squirra (2008), o trabalho de edição/montagem não deve ser tomado como parte natural do processo de criação de um vídeo. Não se pretende nesse estudo enveredar muito adentro no caminho técnico dos meios de produção fílmicos, mas acredita-se ser possível, mesmo para os leigos, reconhecer alguns dos recursos empregados para construir certos sentidos através da observação minuciosa do trabalho de edição e de montagem empregados nas reportagens. A edição/montagem de um filme, segundo Rocha e Lira (2010, p. 1),

envolve o uso de recursos ou efeitos que, no conjunto da obra, ganham significados específicos, agindo como uma espécie de "gramática audiovisual" que, mais do que somente dar dinamismo à narrativa, são também ferramentas de construção de sentido e transmissão de ideias (sic) e impressões desejadas pelo realizador.

Como vem sendo colocado desde as primeiras análises (verbais) das reportagens, a exclusiva responsabilidade do/a professor/a no processo de educação está implicada através, não só da escolha lexical, mas também das relações sintáticas que se formam no decorrer da elaboração do discurso, dentro de orações e entre orações. Porém, o corpus que se está analisando, matérias televisivas, apresenta ainda outro nível em que as relações entre orações e discurso verbal propriamente dito, são construídas - o nível da edição/montagem de imagens e sons.

Assim, além de se atentar para as relações entre orações que fazem parte de uma mesma sequência discursiva verbal, deve-se focar nas relações entre 
sequências discursivas de quadros; focar a forma como são editadas as sequências discursivas verbais e imagéticas nas matérias televisivas. Por exemplo, no $3^{\circ}$ episódio, quando o repórter da Rede Globo, André Luiz Azevedo, diz, em off 7 : "Gustavo loschpe quer entender como é a rotina da aula. Quantas horas de aprendizagem de verdade" (Episódio 03, 5:30 - 5:37) e em seguida passa-se para um novo quadro em que ele e o especialista entrevistam diretamente a professora da escola que tem um conceito baixo de acordo com o Ideb. É importante atentar para o fato de que o comentário feito em locução introduz uma sequência de perguntas em que a professora deve dar as respostas às questões postas pelo repórter: Como é a rotina da aula? Quantas horas há de aprendizagem de verdade? Esse recurso é utilizado nesse trecho para salientar que a quantidade de horas de "aprendizagem de verdade" é de responsabilidade exclusiva da professora Maria Ivonei.

Logo em seguida, no mesmo episódio, tem-se o seguinte trecho também proferido pelo repórter em forma de locução em off: "Na escola pública que recebeu a melhor avaliação, o interesse maior é pelo projeto de reforço na alfabetização. Por isso vamos direto para a sala da professora Josefa do Nascimento" (Episódio 03, 5:55 - 6:05). Aqui se pode dizer que os editores do episódio pretendiam deixar bem claro que o trabalho da professora Josefa do Nascimento seria o motivo da escola receber a melhor avaliação no Ideb. Ao considerarem-se os acarretamentos presentes nesse trecho e no anterior que o antecedeu, vê-se que o ator social responsabilizado pela "aprendizagem de verdade", ou pela boa avaliação no Ideb é o/a professor/a.

Contudo, é interessante notar que nesse segundo trecho, em que se exalta o trabalho da professora Josefa do Nascimento, ela não chega a ser entrevistada pelo repórter ou pelo especialista, mas o que se subentende que seria sua fala é apropriado e proferido pelo especialista Gustavo loschpe. Essa apropriação é reforçada pelo recurso imagético e gestual, pois, ao falar sobre o que acontece na "sala da professora Josefa do Nascimento" o repórter está de costas para a câmera, de pé, em frente ao especialista que está ao lado da professora e que aponta para ela com a mão ao falar. Esse posicionamento lado a lado do especialista e da professora pode sugerir também um alinhamento de pensamento. Aliando-se a isso o fato de que aquilo que é dito pelo especialista é em seguida reiterado pelo repórter e por outros meios gráficos/multimodais (legendas que aparecem na tela enquanto o 
repórter faz a locução em off), atesta-se que a suposta fala da professora estaria de acordo com a visão hegemônica de educação reproduzida nessa série. A Figura 08 ilustra a diferença em relação aos enquadramentos das professoras Maria Ivonei (à esquerda) e Josefa do Nascimento (à direita).

Figura 04 - Blitz Educação, Episódio 03
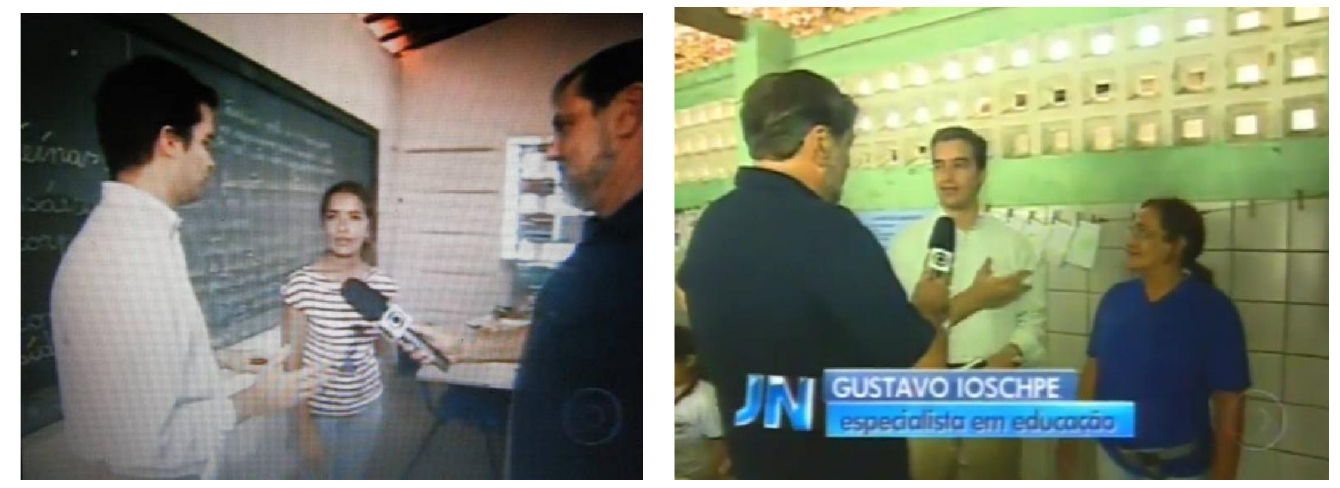

A exemplo de trabalho especificamente de montagem, tem-se várias imagens de crianças escrevendo em cadernos e/ou olhando o/a professor/a no quadro para ilustrar comentários sobre educação realizados em off, normalmente pelo repórter André Luiz Azevedo. A reprodução e insistência nessas imagens, tão recorrentes ao longo da série, sugere uma conceituação de que o processo de ensinoaprendizagem ocorre nesse momento do aluno com o livro/caderno e do/a professor/a no quadro (mais uma vez, numa visão reducionista e tradicionalista de um processo tão complexo). Alguns exemplos dessas imagens e das falas em locução em off seguem abaixo, ilustradas nas Figuras 05 a 08:

Figura 05 - Blitz Educação, Episódio 03. Locução: “horas de aprendizagem de verdade"

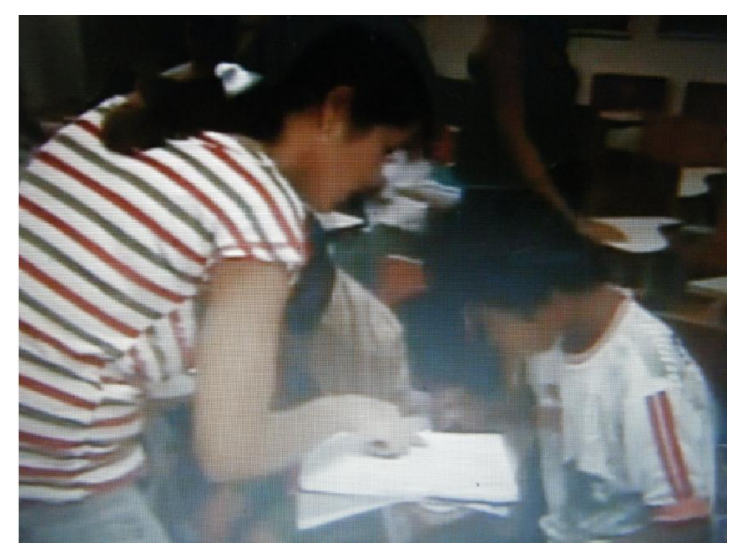


Figura 06 - Blitz Educação, Episódio 04. Locução: "retrato dos professores”

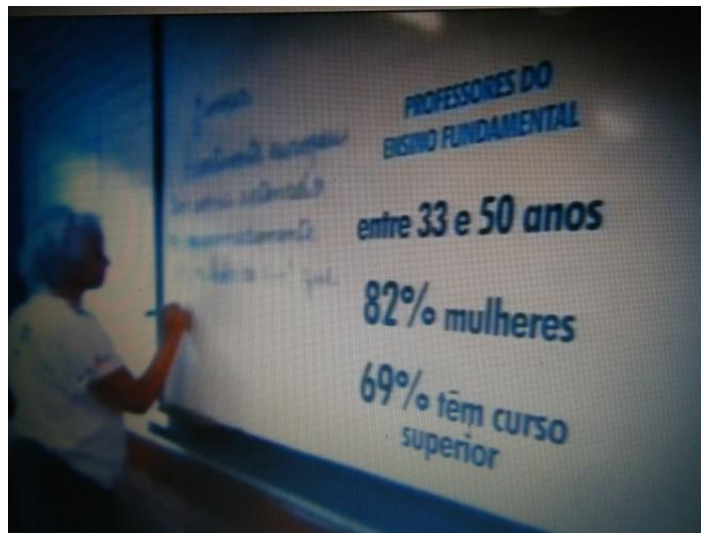

Figura 07 - Blitz Educação, Episódio 04. Locução: “aula do professor

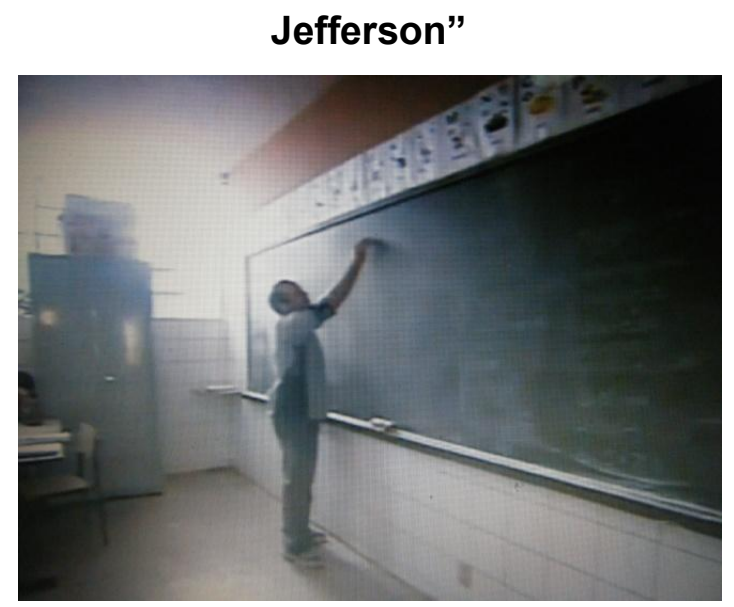

Figura 08 - Blitz Educação, Episódio 06. Locução: "educação de qualidade”

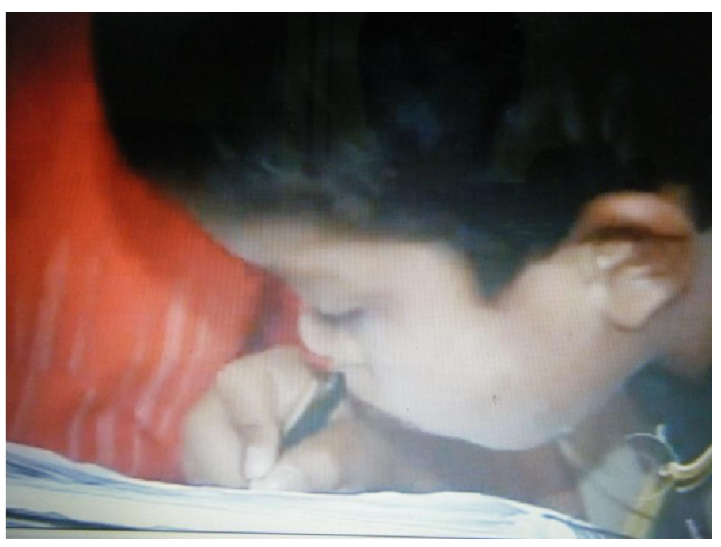

A escolha das imagens que ilustram os comentários não é feita por acaso. $O$ discurso imagético, assim como o verbal, serve como espaço para a formulação e negociação de sentidos, em que se realizam imageticamente proposições sobre certos conceitos. Nesse caso, as proposições ilustradas são: "Estudar (bem, com 
qualidade) é um momento do aluno com o livro/caderno" e "O trabalho do professor é (no quadro) passar informações". Em nenhum momento se ilustra o processo de educação com um debate, uma conversa, uma brincadeira, dentre outras formas de se proceder. É a reprodução de um discurso sobre a educação baseado em conceitos e ideologias conservadoras e tradicionalistas.

\section{CONSIDERAÇÕES FINAIS}

A educação formal sempre foi tema de grande preocupação para as sociedades, desde os antigos gregos, com suas lojas do saber, aos países hoje considerados desenvolvidos que, todavia mostram-se insatisfeitos com o nível de escolaridade que conseguem obter. Essa insatisfação pode ser algo positivo, no sentido de que nos move a sempre estar pensando formas de melhorar a qualidade do ensino. E pode ser algo negativo quando explorada para a reprodução de ideologias que visam à imposição de seu ponto de vista, ao abuso de poder.

Tendo em vista que cada vez mais os debates sobre educação (e outros temas relevantes) acontecem no meio midiático (através de reportagens como "Blitz Educação", por exemplo) tem-se a importância do exame atento dos discursos que circulam nesse domínio. Ainda mais pelo crescente reconhecimento de que no jornalismo, não mais se descobre "a verdade", mas se apresentam "versões de verdades" sobre as coisas. Essas "verdades" implicam, por sua vez, pontos de vista diferentes sobre os fatos, critérios de veracidade divergentes, pontos de relevância distintos, e até juízos de valor sobre os participantes envolvidos diferenciados. Em suma, as diferentes versões para uma mesma notícia, muitas vezes, apontam para diferentes fundações ideológicas.

A série propõe-se a revelar um diagnóstico da educação no Brasil, mas acaba por prescrever uma educação tradicionalista e conservadora como a única solução para os problemas do País. Para tanto, utilizando-se de estratégias como lexicalização, metáforas, naturalização, montagem, edição, etc., estabelece uma dicotomia clara no cerne do tema: há uma educação boa (realizada por professores bons) e há uma educação ruim (realizada por professores ruins). A extrema simplificação com que se trata o tema da educação é indicadora do posicionamento positivista em que se pode objetivamente separar e reduzir as coisas a fim de 
encontrar "a verdade". Esse posicionamento, por sua vez, não é acidental, mas faz parte da visão hegemônica que caracteriza as sociedades capitalistas.

Os estudos do discurso, apoiando-se em análises linguísticas dos textos que concretizam esses discursos, e trazendo à luz o caráter ideológico da linguagem, podem contribuir para a elucidação do abuso de poder, da ilusão de que há uma hegemonia equilibrada, que todos lutam pelos mesmos fins. Brandão (2001, p. 96) diz que "afirmar como idéia ( $\mathrm{sic}$ ) o que nega como prática é o que move o mecanismo da educação autoritária na sociedade desigual”. A análise crítica do discurso (verbal e imagético) construído nos seis episódios da série "Blitz Educação" aponta para essa afirmação de uma ideia (educação de qualidade) que de fato, na prática, serve mais para excluir aqueles que não se adéquam para produzir no sistema capitalista, do que para formar cidadãos numa perspectiva de inclusão. Para criar essa ilusão, utiliza-se primariamente a língua e seus recursos, mas também as imagens e seu potencial como veículo ideológico. Cabe ao analista do discurso, criticamente posicionado, desvelar esses discursos falaciosos, que, caso contrário, podem ser tomados como verdade por uma sociedade que, todavia se apega ao mito da "verdade absoluta" para todos.

\section{NOTAS}

${ }^{1}$ Mestranda em Linguística no Programa de Pós-graduação em Letras da Universidade Federal de Pernambuco (UFPE). Possui graduação em Licenciatura em Letras Português e Espanhol pela Faculdade Frassinetti do Recife (2010) e graduação em Bachelors in Advertising pela Universidade da Georgia (2004). É especialista em Linguística Aplicada a Práticas Discursivas pela Facudade Frassinetti do Recife.

${ }^{2}$ Actors, vectors, e goals no original. Opta-se por manter actors na versão em inglês para que não se confunda com o termo "ator social" da teoria discursiva verbal.

${ }^{3}$ Classification, analytical e symbolic no original.

4 "A social semiotic theory of truth cannot claim to establish the absolute truth or untruth of representations. It can only show whether a given 'proposition' [...] is represented as true or not. From the point of view of social semiotics, truth is a construct of semiosis"

5 "Classification processes do not, of course, simply reflect 'real', 'natural', classifications. For participants to be put together in a syntagm which establishes the classification means that they were judged to be members of the same class, and to be read as such. 'Naturalization' is not natural, whether in images or in language."

${ }^{6}$ Contact, social distance e attitude no original.

${ }^{7}$ Locução em off: quando o comentarista não aparece, mas apenas sua voz é ouvida sobreposta a imagens. 


\title{
EDUCATION, IDEOLOGY AND DISCOURSE: A CRITICAL AND MULTIMODAL ANALYSIS OF THE INVESTIGATIVE SERIES "BLITZ EDUCAÇÃO"
}

\begin{abstract}
In this article we examine the investigative series "Blitz Educação", produced by Rede Globo television station and broadcasted in its main news show, Jornal Nacional in may 2011, in order to elicit the conceptions of formal education disseminated by the media (here represented by the aforementioned TV station), as well as the role assigned to the teacher in the educational process. We seek support in Critical Discourse Analysis, in Norman Fairclough (2001, 2003), making a link with Teun A. van Dijk's ideas on ideology and power relations between social groups $(2006,2010)$ and the multimodal analysis of visual texts proposed by Kress and van Leeuwen (1996). In order to contextualize the pedagogical concepts up for discussion throughout the series, we've discussed the main theories guiding formal education in Brazil today, extracted from the Parâmetros Curriculares Nacionais (1997) among other sources. Keeping in mind that the multimodal semiotic resort is a powerful tool in the construction of discourse, we've examined the montage and editing choices, the representational narrative processes, as well as the representational conceptual constructions employed throughout the series. Finally we've seen how through lexicalization, transitivity and multimodal semiotic recourses, among other strategies, the teacher is framed as being solely responsible for the students' success or failure in the formal educational process. We've also observed how, through discourse (verbal and visual) and supported on this view of the teacher, the investigative series imposes a hegemonic and conservative educational ideology.
\end{abstract}

Keywords: Education. Critical discourse analysis. Multimodality.

\section{REFERÊNCIAS}

BLITZ EDUCAÇÃO. Jornal Nacional. Apresentado por William Bonner e Fátima Bernardes. Rio de Janeiro: Rede Globo, 16 a 21/05/2011.

BRANDÃO, C. R. O que é educação. São Paulo: Brasiliense, 2007.

BRASIL. Lei n. 9394, de 20 de dezembro de 1996. Estabelece as diretrizes e bases da educação nacional. Diário Oficial [da República Federativa do Brasil], Brasília, DF. Disponível em: <http://www.planalto.gov.br/ccivil_03/leis/L9394.htm>. Acesso em: 10 mar. 2012.

BRASIL. Ministério da Educação e Cultura - Secretaria de Educação Básica. Parâmetros curriculares nacionais do Ensino Médio, 1997. Disponível em <http://portal.mec.gov.br/seb/arquivos/pdf/livro01.pdf>. Acesso em 10 mar. 2012.

FAIRCLOUGH, N. Discurso e mudança social. Brasília: UnB, 2001. 
. Analysing discourse: textual analysis for social research. London; New York: Routledge, 2003.

KRESS, G.; VAN LEEUWEN, T. Reading images: the grammar of visual design. London; New York: Routledge, 1996.

MARTINS, A. R. N. Grupos excluídos no discurso da mídia: uma análise de discurso crítica. DELTA - Revista de Documentação de Estudos em Linguística Teórica e Aplicada, vol. 21 (Especial), 2005, p. 129-147.

ROCHA,P.; LIRA, B. S. Percepções do ver - e do não ver - o mundo: o papel da montagem/ edição nos documentários "Janela da Alma" e "A Pessoa é para o que nasce”. Revista Culturas Midiáticas. [on-line]. Ano III, Volume 01. Paraíba: UFPB, jan/jun 2010. Disponível em:

<http://www.cchla.ufpb.br/ppgc/smartgc/uploads/arquivos/06f717184c201010090633 05.pdf>. Acesso em: 10 mar. 2012.

SQUIRRA, S. A força monumental da imagem. Observatório da Imprensa.

Disponível em:

<http://www.observatoriodaimprensa.com.br/news/view/a_forca_monumental_da_im agem> Acesso em 10 mar. 2012.

THOMPSON, J. B. Ideologia e cultura moderna: teoria social crítica na era dos meios de comunicação de massa. Petrópolis: Vozes, 1995.

VAN DIJK, T. A. ideología: una aproximación multidisciplinaria. Barcelona, España: Gedisa, 2006.

. Discurso e poder. 2 ed. São Paulo: Contexto, 2010. 